\title{
The Key Role of Ambulatory Blood Pressure Monitoring in the Detection of Masked Hypertension and Other Phenomena in Frail Geriatric Patients
}

\author{
Marek Koudelka $^{1,2, *}$ and Eliška Sovová ${ }^{1}$ \\ 1 Department of Exercise Medicine and Cardiovascular Rehabilitation, Palacký University Olomouc and \\ University Hospital Olomouc, 77520 Olomouc, Czech Republic; eliska.sovova@fnol.cz \\ 2 Department of Internal Medicine, FRANZISKUS SPITAL GmbH, Landstraßer Hauptstraße 4a, \\ 1030 Vienna, Austria \\ * Correspondence: koudelka.marek.md@gmail.com; Tel.: +43-1-71126; Fax: +43-1-711269968
}

Citation: Koudelka, M.; Sovová, E. The Key Role of Ambulatory Blood Pressure Monitoring in the Detection of Masked Hypertension and Other Phenomena in Frail Geriatric Patients. Medicina 2021, 57, 1221. https:// doi.org/10.3390/medicina57111221

Academic Editor: Vita Lesauskaitè

Received: 3 October 2021

Accepted: 5 November 2021

Published: 9 November 2021

Publisher's Note: MDPI stays neutral with regard to jurisdictional claims in published maps and institutional affiliations.

Copyright: (c) 2021 by the authors. Licensee MDPI, Basel, Switzerland. This article is an open access article distributed under the terms and conditions of the Creative Commons Attribution (CC BY) license (https:// creativecommons.org/licenses/by/ $4.0 /)$.

\begin{abstract}
Background and Objectives: This study aims to determine prevalence of masked uncontrolled hypertension (MUH) in frail geriatric patients with arterial hypertension and thus show the role of ambulatory blood pressure monitoring (ABPM) since hypertension occurs in more than $80 \%$ of people $60+$ years and cardiovascular diseases are the main cause of death worldwide. Despite modern pharmacotherapy, use of combination therapy and normal office blood pressure (BP), patients' prognoses might worsen due to inadequate therapy (never-detected MUH). Materials and Methods: 118 frail geriatric patients (84.2 \pm 4.4 years) treated for arterial hypertension with office $\mathrm{BP}<140 / 90 \mathrm{mmHg}$ participated in the study. 24-h ABPM and clinical examination were performed. Results: Although patients were normotensive in the office, 24-h measurements showed that BP values in $72 \%$ of hypertensives were not in the target range: MUH was identified in 47 (40\%) patients during $24 \mathrm{~h}$, in 48 (41\%) patients during daytime and nocturnal hypertension in 60 (51\%) patients. Conclusions: ABPM is essential for frail geriatric patients due to high prevalence of MUH, which cannot be detected based on office BP measurements. ABPM also helps to detect exaggerated morning surge, isolated systolic hypertension, dipping/non-dipping, and set and properly manage adequate treatment, which reduces incidence of cardiovascular events and contributes to decreasing the financial burden of society.
\end{abstract}

Keywords: ambulatory blood pressure monitoring (ABMP); frailty; geriatric patient; masked hypertension; masked uncontrolled hypertension

\section{Introduction}

High blood pressure (BP) remains the leading cause of morbidity and mortality worldwide. Every year, 7.6 million people die from hypertension, more than half of them are 45-69 years old [1]. It is alarming that in an ever-increasing group of people over 60, hypertension occurs in more than $80 \%$ of individuals [2]. In patients older than 80 years, the prevalence can be as high as $90 \%$ [3]. However, BP values increasing with age cannot be considered a normal and benign manifestation of aging. People who have normal $\mathrm{BP}$ in old age have the best cardiovascular $(\mathrm{CV})$ prognosis. The risk group represents especially geriatric patients with very low or hardly any functional reserves (we speak of frail seniors). Geriatric frailty is generally reported in $10 \%$ of individuals aged $\geq 65$ years and in $25-30 \%$ of individuals aged $\geq 85$ years [4]. It significantly affects the patient's prognosis and adjustment of medication is required to reduce the risk of fatal and non-fatal $\mathrm{CV}$ or cerebrovascular complications. Adverse drug effects and consequences of incorrect prescription are the most common causes of health alteration and hospitalization of geriatric patients. Rational and individualized pharmacotherapy is therefore an important part of geriatric patient care. 
Essential hypertension and more severe target organ damage are more common in elderly patients than in the younger population. Hypertension occurs in individuals with a higher prevalence of coronary heart disease, myocardial infarction, diastolic dysfunction, a tendency to arrhythmia, and cerebral arteriosclerosis and peripheral arterial disease in general. Other factors such as diabetes, lung disease, depression, neoplasia, and others should also be considered when deciding on diagnosis and treatment [5].

If $\mathrm{BP}$ values $\geq 140 / 90 \mathrm{mmHg}$ are repeatedly found in geriatric patients (previous recommendations were more conservative mentioning values $160 / 100 \mathrm{mmHg}$ but findings from recent studies confirm that older patients also benefit from the treatment of grade 1 hypertension), their treatment should start and aim to lower BP to values below $140 / 90 \mathrm{mmHg}$ following the latest recommendations (patients aged $65+$ years should have systolic blood pressure (SBP) values between 130 and $140 \mathrm{mmHg}$ and diastolic blood pressure (DBP) values below $80 \mathrm{mmHg}$ [6]). The correct compensation can be then checked using ambulatory blood pressure monitoring (ABPM), with arbitrarily set values for 24-h, daytime and nighttime averages regardless of age. Recently, there have been discussions as to whether the treatment of hypertension in elderly and frail geriatric patients is effective and cost-effective despite their advanced age. Many placebo-controlled studies (e.g., SHEP [7], SYST-EUR [8], Beckett et al. [9]) show that the treatment of hypertension significantly reduces the risk of CV events in the elderly. The conclusions of the HYVET study [10] demonstrate that antihypertensive treatment is effective and positively affects the prognosis in patients aged $\geq 80$ years with a significant reduction in the incidence of heart failure, fatal stroke, and overall mortality. Also, Williamson et al. [11] studying patients aged 75 years or older reported that treating to an SBP target $<120 \mathrm{mmHg}$ (compared with an SBP target $<140 \mathrm{mmHg}$ ) resulted in significantly lower rates of fatal and nonfatal major CV events and death from any cause. However, PARTAGE [12] study focusing on frail patients ( $>80$ years) shows a significant interaction between low SBP $(<130 \mathrm{mmHg})$ and treatment with 2 or more BP-lowering agents, resulting in a higher risk of mortality. Excessive reduction of the BP in the frail geriatric patients, especially in individuals with $\mathrm{CV}$ disease, might be detrimental, probably due to a hypoperfusion of target organs [12]. Current 2018 ESC/ESH Guidelines states that the intended target SBP for all patients elder than 65 years is $130-139 \mathrm{mmHg}$ if achievable and tolerated as any BP lowering towards this target is likely to be beneficial. However, it is recommended to avoid treated SBP values of $<130 \mathrm{mmHg}$ [6].

ABPM provides more BP measurements, reflects the duration and efficacy of antihypertensive medication over a $24-\mathrm{h}$ period, provides information on nocturnal BP, and more reproducible information than occasional measurements in the office. Thus, thanks to $\mathrm{ABPM}$, we can detect masked hypertension $(\mathrm{MH})$, which is defined as normal $\mathrm{BP}$ in the clinic or office $(<140 / 90 \mathrm{mmHg})$ but increased BP outside the office and medical centers (ambulatory daytime BP or home BP > 135/85 mmHg) [10]. Masked hypertension occurs in 10-20\% [13] or even up to $30 \%$ of patients [6]. Initial markers of $\mathrm{MH}$ are considered to be nocturnal hypertension and non-dipping [14]. Yano and Bakris [15] suggested that MH can be classified based on masked daytime versus masked nighttime patterns. One group of patients may show selective daytime MH when they are exposed to job strain, mental stress, smoking, excessive drinking, or poor exercise tolerance. On the other hand, nocturnal $\mathrm{MH}$ can be seen in patients with sleep deprivation, obstructive sleep apnea, metabolic syndrome, diabetes, or chronic kidney disease. In many patients, both can be observed.

Studies show that patients with $\mathrm{MH}$ are more likely to experience $\mathrm{CV}$ events as a result of high $\mathrm{BP}$ and thus $\mathrm{MH}$ pose a higher risk than white coat hypertension also in elderly patients [16]. These patients experience more severe damage to target organs as well. Masked hypertension often occurs in patients with chronic kidney disease and leads to faster progression of renal failure [17]. Undiagnosed and untreated $\mathrm{MH}$ and treated but uncontrolled $\mathrm{MH}$ are two significant high-risk factors impacting public health [14]. 
Franklin et al. [14] mention that the risk of $\mathrm{MH}$ is higher in smokers and individuals who consume alcohol excessively, in people experiencing stress (when measured in the office they may show normal BP values, BP increases in stressful situations), in individuals with sleep deprivation or sleep apnea, in elderly men due to decreased baroreceptor sensitivity and increased BP variability, in obese individuals, patients with diabetes or longer duration of hypertension. Each of these characteristics increases the risk of cardiovascular diseases (CVD).

The objective of this study is to determine the prevalence of masked uncontrolled hypertension (MUH) in frail geriatric patients with arterial hypertension and thus show the role of $A B P M$ in group of frail geriatric patients.

\section{Materials and Methods}

We studied consecutively a sample of 118 geriatric patients treated for arterial hypertension ( $42 \mathrm{men}$ ), mean age $84.2 \pm 4.4$ years, who had office BP $<140 / 90 \mathrm{mmHg}$. Patients were seated comfortably in a quiet environment for $5 \mathrm{~min}$ before the beginning of BP measurements. Three BP measurements were recorded, 1-2 min apart. We performed additional measurement if the first two readings differed by $>10 \mathrm{mmHg}$. BP was recorded as the average of the last two BP readings. We used standard bladder cuff and measured the BP in a seated position in all patients following the ESC/ESH guidelines [6]. The measurement was taken by a regularly calibrated standard sphygmomanometer. Furthermore, patients underwent clinical examinations, including heart rate and electrocardiography (ECG) measurements. We assessed frailty in patients using the frailty index because it is complex and precise (in comparison to, e.g., the Barthel test). Frailty index takes into account both physical and psychosocial aspects of frailty and also cognitive functions. The frailty index was calculated as the number of deficits in a patient divided by all considered deficits (70 clinical deficits from the CSHA clinical assessment including the presence and severity of current diseases, ability in ADLs and physical signs from clinical and neurologic exams) [18]. To indicate severity, each deficit not restricted by its nature to two values (i.e., 0 or 1 for absence or presence, respectively) was assigned three $(0,0.5$ or 1$)$ or four values $(0,0.33,0.67$ or 1.0$)$, as appropriate. The frailty index ranges from 0.00 to 1.00 , a higher value indicates a frailer (worse) status. The Mobil-O-Graph ${ }^{\circledR}$ NG was used for ABPM performed at patient's habitation in accordance with the currently valid ESC/ESH guidelines [6]. BP was measured every 20 min during the daytime (6 a.m.-10 p.m.) and every $30 \mathrm{~min}$ at nighttime (10 p.m. -6 a.m.). Target BP values were the following: mean $\mathrm{BP}$ (MBP) 130/80 mmHg during $24 \mathrm{~h}$; MBP 135/85 mmHg during the daytime and MBP $120 / 70 \mathrm{mmHg}$ during the nighttime [6,15]. ABPM was considered successful when the record provided a minimum of 20 valid daytime and 7 nighttime measurements, and at least $70 \%$ of the expected 24-h readings were valid in accordance with ESC/ESH guidelines [6].

As MH were considered SBP $\geq 130$ and/or DBP $\geq 80 \mathrm{mmHg}$ during $24 \mathrm{~h}$; SBP $\geq 135$ and/or DBP $\geq 85 \mathrm{mmHg}$ during the daytime and SBP $\geq 120$ and/or DBP $\geq 70 \mathrm{mmHg}$ during the nighttime.

Isolated systolic hypertension was defined as $\mathrm{SBP} \geq 140$ and $\mathrm{DBP}<90 \mathrm{mmHg}$.

Patients with malignant disease, patients using nonsteroidal anti-inflammatory drugs, patients with diagnosed secondary hypertension, and patients whose life expectancy is due to malignant or chronic disease less than 1 year were not included.

\section{Results}

Basic clinical parameters are shown in Table 1.

Average office BP and ABPM BP results are shown in Table 2.

Distribution of number and percentage of patients based on various aspects circadian rhythm are shown in Table 3 and graphically displayed in Figure 1. 
Table 1. Basic clinical parameters.

\begin{tabular}{ccc}
\hline \multicolumn{3}{c}{ Basic Clinical Parameters Sample $(\boldsymbol{n}=\mathbf{1 1 8})$ Mean \pm SD } \\
\hline Gender & Male $(n=42)$ & Female $(n=76)$ \\
\hline Patients & 42 & 76 \\
\hline Age & $81.6 \pm 4.4$ & $87.1 \pm 6.2$ \\
\hline Weight $(\mathrm{kg})$ & $74.2 \pm 17.2$ & $70.2 \pm 15.8$ \\
\hline Height $(\mathrm{cm})$ & $178.9 \pm 9.1$ & $161.1 \pm 9.1$ \\
\hline Body mass index & $24.3 \pm 5.4$ & $22.1 \pm 4.4$ \\
\hline Frailty Index (points) & $0.6 \pm 0.2$ & $0.5 \pm 0.2$ \\
\hline
\end{tabular}

Table 2. Average BP results.

\begin{tabular}{llcc}
\hline BP Measurement & Time Period & Systolic MBP (mmHg) & Diastolic MBP $(\mathbf{m m H g})$ \\
\hline & & $(\boldsymbol{n}=\mathbf{1 1 8})$ Mean \pm SD & \\
\hline \multirow{2}{*}{ Office BP } & & $126.1 \pm 8.1$ & $74.9 \pm 6.9$ \\
\hline \multirow{2}{*}{ ABPM } & $24 \mathrm{~h}$ & $124.3 \pm 29.8$ & $72.8 \pm 13.9$ \\
& Daytime & $125.9 \pm 30.2$ & $74.6 \pm 12.9$ \\
& Nighttime & $124.1 \pm 32.1$ & $70.9 \pm 15.1$ \\
\hline
\end{tabular}

$\overline{\mathrm{BP}}=$ blood pressure, $\mathrm{MBP}=$ mean blood pressure, $\mathrm{ABPM}=$ ambulatory blood pressure monitoring.

Table 3. Correct BP compensation and prevalence of masked/nocturnal hypertension $(n=118)$.

\begin{tabular}{ccc}
\hline & N & $\%$ \\
\hline $\begin{array}{c}(n=118) \\
\text { Correct office BP compensation (target values) }\end{array}$ & 118 & 100 \\
\hline Correct ABPM compensation (target values): & 33 & 28 \\
24 h systolic + diastolic BP & 33 & 28 \\
24 h systolic BP & 33 & 28 \\
24 h diastolic BP & 60 & 51 \\
Daytime systolic + diastolic BP & 33 & 28 \\
Daytime systolic BP & 33 & 28 \\
Daytime diastolic BP & 49 & 58 \\
Night systolic + diastolic BP & 8 & 7 \\
Night systolic BP & 15 & 13 \\
Night diastolic BP & 35 & 30 \\
Masked hypertension: & 85 & 72 \\
Masked hypertension (abnormal avg. 24 h) & 47 & 40 \\
Masked hypertension (abnormal daytime) & 48 & 41 \\
Nocturnal hypertension & 60 & 51 \\
\hline
\end{tabular}

Antihypertensive therapy in patients included angiotensin-converting enzyme (ACE) inhibitors, angiotensin receptor blockers (ARBs), beta blockers, calcium channel blockers (CCBs), centrally acting antihypertensives and diuretics. Distribution of antihypertensive medication can be seen in Table 4 .

Patients had the following medical history: 48 patients $(41 \%)$ had ischemic heart disease, 26 patients $(22 \%)$ had ischemic disease of the lower extremities, 10 patients $(8 \%)$ had stroke/transient ischemic attack (TIA), 37 patients (31\%) had diabetes mellitus and prediabetes (IGT) and 352 patients (30\%) had atrial fibrillation.

ECG detected silent myocardial infarction in 8 patients, arrhythmia (mostly the atrial fibrillation) appeared in 38 patients. There was no prevalence in group of patients with MUH.

All 118 patients participated until the end of this study and are still being monitored. ABPM revealed MUH in 85 patients (72\%): 47 patients (40\%) during $24 \mathrm{~h}$, in 48 patients (41\%) during the daytime and only nocturnal hypertension was observed even in 60 patients (51\%). 
An exaggerated morning surge in BP occurred in $20(17 \%)$ individuals. Isolated systolic hypertension was observed in $79(67 \%)$ patients.
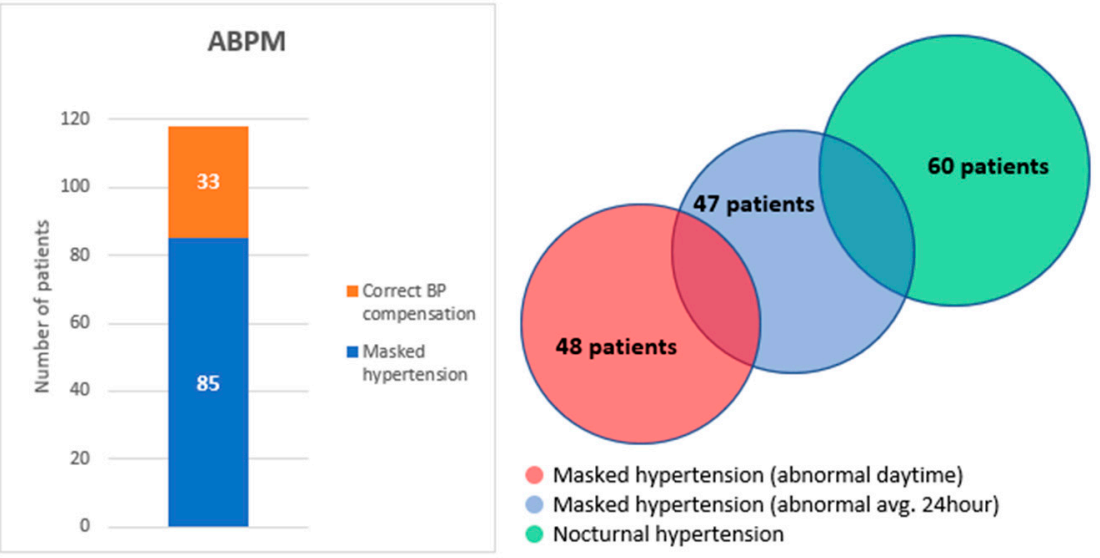

Figure 1. Correct BP compensation and prevalence of masked/nocturnal hypertension $(n=118)$. $\mathrm{BP}=$ blood pressure, $\mathrm{ABPM}=$ ambulatory blood pressure monitoring.

Table 4. Antihypertensive medication.

\begin{tabular}{cll}
\hline & $N$ & $\%$ \\
\hline ACE inhibitors & 67 & 57 \\
\hline Angiotensin receptor blockers (ARBs) & 39 & 33 \\
\hline Calcium channel blockers (CCBs) & 62 & 53 \\
\hline Diuretics & 43 & 36 \\
\hline Beta blockers & 38 & 32 \\
\hline Centrally acting antihypertensives & 19 & 16 \\
\hline Monotherapy & 27 & 23 \\
\hline Dual therapy & 32 & 27 \\
\hline Triple therapy & 59 & 50 \\
\hline
\end{tabular}

\section{Discussion}

Prevalence of MUH in fragile geriatric patients has not received much attention yet as evidenced by the lack of available research data. In our study, all patients were normotensive when measured $\mathrm{BP}$ in the office and were therefore expected to have well-controlled hypertension. However, ABPM surprisingly detected masked hypertension in almost $3 / 4$ of the patients: $40 \%$ showed abnormal BP average during $24 \mathrm{~h}, 41 \%$ daytime and $51 \%$ nocturnal MH. Our findings are similar to findings of Cacciolati et al. [19], who based on daytime HBPM reported $\mathrm{MH}$ in $41 \%$ of patients aged $\geq 75$ years with normal BP values in the office. They report that MH increased sharply with the level of office SBP (from $22 \%$ in patients with SBP $<120 \mathrm{mmHg}$ to $48 \%$ in patients with SBP $\geq 130 \mathrm{mmHg}$ ). Other major risk factors are male gender, diabetes, age $80+$, antihypertensive use, and e.g., $\mathrm{BMI} \geq 25 \mathrm{~kg} / \mathrm{m}^{2}$. The high frequency of $\mathrm{MH}$ in the elderly may be partly explained by the aging-related decrease of the baroreflex and the increased BP variability [19]. Ohkubo et al. [20] mention that MH is also associated with increased $\mathrm{CV}$ risk in women and treated patients, regardless of numbers of risk factors or $\mathrm{CV}$ complications. Even in patients with low $\mathrm{CV}$ risk, $\mathrm{MH}$ leads to a significantly higher risk of stroke and CV mortality [20,21]. Also, Bobrie et al. [22] inform that MUH is associated with an increased risk of CVD even in individuals treated with antihypertensives. Franklin et al. [23] reported MH in $44.5 \%$ of untreated middle-aged and elderly patients, in another study [24], $\mathrm{MH}$ prevalence with untreated was $18.8 \%$ but $30.5 \%$ in treated patients. Moreover, normotensive diabetic patients had a prevalence of $\mathrm{MH}$ of $29.3 \%$ when untreated and $42.5 \%$ with treatment. Thus, prevalence of $\mathrm{MH}$ is 
not only influenced by diabetes mellitus and other high-risk disease but also by antihypertensive treatment since treatment aimed at normalizing conventional office BP will increase the percentage of patients with MUH [25] when ABPM is not involved in the treatment management.

According to Pierdomenico et al. [16], elderly patients with MUH had a significantly higher $\mathrm{CV}$ risk after treatment with various covariates than patients with controlled hypertension.

Nocturnal hypertension was present in $60(51 \%)$ patients. Available data show that nocturnal hypertension causes a significant increase in CVD and CV morbidity and mortality. Patients with coexistence of blunted SBP decline have the worst risk profile [4]. Agarwal et al. [26] reported that almost $60 \%$ of patients treated for chronic kidney disease had MUH, which was diagnosed exclusively $24 \%$ of the time in nocturnal ABPM. Nocturnal hypertension leads to faster chronic kidney disease progression [27]. ABPM is thus very beneficial, especially to these patients, for its contribution to the diagnosis and treatment of nocturnal $\mathrm{BP}$, which is almost always elevated in patients with moderate to severe renal impairment [28].

Higher nocturnal BP and non-dipping is also associated with slower walking speed $[4,29]$. Decreased mobility during the day in frail seniors can lead to a decrease in physical activity, which can in turn affect daytime BP and lead to the disappearance of nocturnal BP dipping [30]. As shown by J-SHIPP study [31], nocturnal BP is associated with mild cognitive dysfunction in the elderly. According to Garcia et al. [5], along with high nocturnal SBP and non-dipping, increased BP variability is also considered an important determinant of cognitive impairment. Furthermore, 24-h SBP has been shown to be an independent factor for brain atrophy in the elderly [32]. Even though association of BP and cognitive performance is diversified in people elder than 65 years, with more studies showing the worse cognitive function with high or low BP, (in contrast to younger individuals in which high BP is linked to cognitive impairment) [33], strict control of BP, including nighttime, is recommended as it can have a neuroprotective effect and prevent the occurrence of dementia. It is suggested that ABPM may help with an early diagnosis of mild cognitive impairment (MCI) since CV and neuro-cognitive systems operate in relation and suboptimal BP can be considered an early biomarker of cognitive impairment [33]. Prescription of evening antihypertensives is often necessary to improve the prognosis in patients with nocturnal hypertension. Moreover, antihypertensive therapy might also reduce the risk of developing cognitive impairment as suggested by different studies [33].

An exaggerated morning surge in BP was observed in $20(17 \%)$ patients. Morning rise in $\mathrm{BP}$ is a common physiological process, but an exaggerated surge in $\mathrm{BP}$ in the morning hours after waking and getting up is a serious risk factor, especially for frail geriatric patients. Abnormal morning surge is when SBP values are higher than $50 \mathrm{mmHg}$ and/or DPB values are higher than $22 \mathrm{mmHg}$ between 6 a.m. and 10 a.m. compared to the nocturnal MBP. Exaggerated morning BP may be a sign of insufficient choice of antihypertensive regimen, e.g., administration of short-acting or medium-acting drugs, undermedication or none/insufficient use of combination therapy.

A very frequent phenomenon in our target group detected in $79(67 \%)$ patients was also isolated systolic hypertension, i.e., $\mathrm{SBP} \geq 140 \mathrm{mmHg}$ and $\mathrm{DBP}<90 \mathrm{mmHg}$, which increases with age. These findings are similar to results of NHANES III [34] study where isolated systolic hypertension occurred in $87 \%$ of individuals in the group of patients $60+$ years. Isolated systolic hypertension with increased pulse BP occurs due to the loss of arterial elasticity in geriatric patients. Decreased arterial compliance and increased pulse pressure are associated with up to 4 times higher risk of myocardial infarction, left ventricular hypertrophy, renal dysfunction, stroke, and CV mortality [35].

The above-mentioned trends show the importance of treatment control using ABPM even in fragile geriatric patients since it provides additional data for treatment management. Although we currently have the means of modern pharmacology and practice effective combination therapy in the patient, our research shows that proper BP compensation is only achieved in some patient because quite often the treatment of hypertension does not involve 
24-h monitoring, both at the beginning and after certain periods during the treatment. When the diagnosis and treatment are indicated, BP measurements are often performed only in the office which seems to be insufficient for the adequate treatment. It is very important to know the complex $24 \mathrm{~h} \mathrm{BP}$ profile of the patient. Despite the unclarity whether using ambulatory BP values to guide therapy in patients with MUH leads to reduction of morbidity and mortality [6], our study shows that ABMP is a great complementary alternative in treatment management and the right dosage of medication. It not only provides more data for better estimation of $\mathrm{CV}$ events than clinical BP measurements, offers tailor-made treatment and tailoring therapy to an individual BP profile, and can help us address daily life situations (explain stress-related BP increases, detect an in/sufficient decrease during the sleep, and identify over/or under-treatment), but it is thus currently the most accurate and potentially most cost-effective. Moreover, using ABPM does not cause white coat hypertension in patients. ABPM should be performed with each patient who has an elevated BP $\geq 140 / 90 \mathrm{mmHg}$ recorded by any measurement method (if ABPM is rejected or not tolerated, home BP measurement is recommended). Once the treatment is initiated, we recommend that ABPM is repeated after a few weeks to determine whether the treatment is effective and the decrease in BP is adequate. As an example, in RAMBLER study [36], treatment in $38 \%$ of patients was adapted thanks to ABPM, $32 \%$ of patients initiated new treatment, and $14 \%$ of untreated patients with elevated office BP who were candidates for drug treatment did not initiate treatment because ABPM values were normal.

It should be noted that treatment aiming at normalization of conventional BP in the office and ignoring out-of-office BP measurements may lead to an increase in the percentage of patients with MUH. ABPM is a key tool for a correct management and prognosis in this subpopulation [21,25]. If individuals with $\mathrm{MH}$ are not detected, they will remain untreated or insufficiently controlled and may experience $\mathrm{CV}$ complications and target organ damage. The quality of life of patients will thus decrease and unnecessary costs for medical care will increase. Despite initial expenditures, ABPM seems to be ultimately cost-effective due to improved BP control, reduction of CV consequences of hypertension, and decreased costs of subsequent treatment. At the same time, the use of ABPM would determine the true level of BP and improve currently "poor" control level of hypertension.

\section{Conclusions}

The results of our study show that for the appropriate treatment setting, it is important to perform 24-h BP measurements even in frail geriatric hypertensive patients with normotensive office BP values. High incidence of MUH in our group manifests the role of ABPM, which is key for management and adequate treatment of frail geriatric patients, also because it detects other phenomena such as exaggerated morning surge and isolated systolic hypertension. As suggested by other studies, their detection and treatment leads to decrease in the incidence of cardiovascular events. Thus, we expect that it also might reduce the financial burden of the society. The further research is needed to confirm the cost-effectiveness of this approach.

Author Contributions: This research was conducted by M.K. He collected, analyzed and interpreted data of all patients, researched studies and available literature. M.K. wrote the core of the article, E.S. reviewed it and provided advice and consultations. Both authors, M.K. and E.S., read and approved the final version of the manuscript. All authors have read and agreed to the published version of the manuscript.

Funding: This research did not receive any specific grant from funding agencies in the public, commercial or not-for-profit sectors.

Institutional Review Board Statement: We confirm that the research was conducted and performed in compliance with relevant regulations and guidelines. All patients, who were subjects of the research, provided the informed consent with inclusion and further data processing before participating in this study. All procedures performed in this research followed the ethical standards of the institutional and/or national research committee, the 1964 Helsinki declaration and its later 
amendments and comparable ethical standards. The local ethics committee, the University Hospital and Faculty of Medicine and Dentistry, Palacký University Olomouc, Ethics Committee approved this research as number EK FNOL 76/08 (approved in July 2008). This research was supervised by Eliška Sovová, Head of Department of Exercise Medicine and Cardiovascular Rehabilitation, Vice-Dean for Legislation, Faculty Organization, and performed at the University Hospital Olomouc.

Informed Consent Statement: The informed consent was signed by all patients included in this study. They agreed to take part in this study and gave consent to use of their data for the study/manuscript.

Data Availability Statement: The corresponding authors can provide datasets, which were collected, used and analyzed in this study, on a reasonable request.

Conflicts of Interest: The authors declare no conflict of interest.

\section{References}

1. Lawes, C.M.; Hoorn, S.V.; Rodgers, A. International Society of Hypertension. Global burden of blood-pressure-related disease, 2001. Lancet 2008, 371, 1513-1518. [CrossRef]

2. Lloyd-Jones, D.; Morris, P.B.; Ballantyne, C.M.; Birtcher, K.K.; Daly, D.D.; DePalma, S.; Minissian, M.B.; Orringer, C.E.; Smith, S.C. 2017 Focused Update of the 2016 ACC Expert Consensus Decision Pathway on the Role of Non-Statin Therapies for LDL-Cholesterol Lowering in the Management of Atherosclerotic Cardiovascular Disease Risk: A Report of the American College of Cardiology Task Force on Expert Consensus Decision Pathways. J. Am. Coll Cardiol. 2017, 70, 1785-1822. [CrossRef] [PubMed]

3. Wang, Y.; Wang, Q.J. The prevalence of prehypertension and hypertension among US adults according to the new joint national committee guidelines: New challenges of the old problem. Arch. Intern. Med. 2004, 164, 2126-2134. [CrossRef]

4. Gijón-Conde, T.; Graciani, A.; López-García, E.; García-Esquinas, E.; Laclaustra, M.; Ruilope, L.M.; Rodríguez-Artalejo, F.; Banegas, J.R. Frailty, Disability, and Ambulatory Blood Pressure in Older Adults. J. Am. Med. Dir. Assoc. 2018, 19, 433-438. [CrossRef] [PubMed]

5. Mediavilla García, J.D.; Jaén Águila, F.; Fernández Torres, C.; Gil Extremera, B.; Jiménez Alonso, J. Ambulatory blood pressure monitoring in the elderly. Int. J. Hypertens. 2012, 2012, 548286. [CrossRef] [PubMed]

6. Williams, B.; Mancia, G.; Spiering, W.; Rosei, E.A.; Azizi, M.; Burnier, M.; Clement, D.L.; Coca, A.; de Simone, G.; Dominiczak, A.; et al. 2018 ESC/ESH Guidelines for the management of arterial hypertension: The Task Force for the management of arterial hypertension of the European Society of Cardiology and the European Society of Hypertension. J. Hypertens. 2018, 36, 1953-2041. [CrossRef] [PubMed]

7. SHEP Cooperative Research Group. Prevention of stroke by antihypertensive drug treatment in older persons with isolated systolic hypertension. Final results of the Systolic Hypertension in the Elderly Program (SHEP). JAMA 1991, 265, 3255-3264. [CrossRef]

8. Gasowski, J.; on behalf of the Systolic Hypertension in Europe Investigators; Staessen, J.; Celis, H.; Fagard, R.; Thijs, L.; Birkenhäger, W.; Bulpitt, C.; Fletcher, A.; Arabidze, G.; et al. Systolic Hypertension in Europe (Syst-Eur) trial phase 2: Objectives, protocol, and initial progress. Systolic Hypertension in Europe Investigators. J. Hum. Hypertens. 1999, 13, 135-145. [CrossRef]

9. Beckett, N.S.; Peters, R.; Fletcher, A.E.; Staessen, J.A.; Liu, L.; Dumitrascu, D.; Stoyanovsky, V.; Antikainen, R.L.; Nikitin, Y.; Anderson, C.; et al. Treatment of hypertension in patients 80 years of age or older. N. Engl. J. Med. 2008, 358, 1887-1898. [CrossRef] [PubMed]

10. Bulpitt, C.; Fletcher, A.; Beckett, N.; Coope, J.; Gil-Extremera, B.; Forette, F.; Nachev, C.; Potter, J.; Sever, P.; Staessen, J.A.; et al. Hypertension in the Very Elderly Trial (HYVET): Protocol for the main trial. Drugs Aging 2001, 18, 151-164. [CrossRef] [PubMed]

11. Williamson, J.D.; Supiano, M.A.; Applegate, W.B.; Berlowitz, D.; Campbell, R.C.; Chertow, G.M.; Fine, L.J.; Haley, W.E.; Hawfield, A.T.; Ix, J.H.; et al. Intensive vs Standard Blood Pressure Control and Cardiovascular Disease Outcomes in Adults Aged $\geq 75$ Years: A Randomized Clinical Trial. JAMA 2016, 315, 2673-2682. [CrossRef] [PubMed]

12. Benetos, A.; Labat, C.; Rossignol, P.; Fay, R.; Rolland, Y.; Valbusa, F.; Salvi, P.; Zamboni, M.; Manckoundia, P.; Hanon, O.; et al. Treatment With Multiple Blood Pressure Medications, Achieved Blood Pressure, and Mortality in Older Nursing Home Residents: The PARTAGE Study. JAMA Intern. Med. 2015, 175, 989-995. [CrossRef] [PubMed]

13. Kawano, Y.; Horio, T.; Matayoshi, T.; Kamide, K. Masked hypertension: Subtypes and target organ damage. Clin. Exp. Hypertens. 2008, 30, 289-296. [CrossRef] [PubMed]

14. Franklin, S.S.; O’Brien, E.; Staessen, J.A. Masked hypertension: Understanding its complexity. Eur. Heart J. 2017, 38, 1112-1118. [CrossRef]

15. Yano, Y.; Bakris, G.L. Recognition and management of masked hypertension: A review and novel approach. J. Am. Soc. Hypertens. 2013, 7, 244-252. [CrossRef] [PubMed]

16. Pierdomenico, S.D.; Pierdomenico, A.M.; Coccina, F.; Porreca, E. Prognosis of Masked and White Coat Uncontrolled Hypertension Detected by Ambulatory Blood Pressure Monitoring in Elderly Treated Hypertensive Patients. Am. J. Hypertens. 2017, 30, 1106-1111. [CrossRef]

17. Babu, M.; Drawz, P. Masked Hypertension in CKD: Increased Prevalence and Risk for Cardiovascular and Renal Events. Curr. Cardiol. Rep. 2019, 21, 58. [CrossRef] 
18. Rockwood, K.; Song, X.; MacKnight, C.; Bergman, H.; Hogan, D.B.; McDowell, I.; Mitnitski, A. A global clinical measure of fitness and frailty in elderly people. CMAJ 2005, 173, 489-495. [CrossRef]

19. Cacciolati, C.; Hanon, O.; Alpérovitch, A.; Dufouil, C.; Tzourio, C. Masked hypertension in the elderly: Cross-sectional analysis of a population-based sample. Am. J. Hypertens. 2011, 24, 674-680. [CrossRef]

20. Ohkubo, T.; Kikuya, M.; Metoki, H.; Asayama, K.; Obara, T.; Hashimoto, J.; Totsune, K.; Hoshi, H.; Satoh, H.; Imai, Y. Prognosis of "masked" hypertension and "white-coat" hypertension detected by 24-h ambulatory blood pressure monitoring 10-year follow-up from the Ohasama study. J. Am. Coll Cardiol. 2005, 46, 508-515. [CrossRef]

21. Spannella, F.; Filipponi, A.; Giulietti, F.; Balietti, P.; Bernardi, B.; Rosettani, G.; Sarzani, R. Prognostic role of masked and white-coat hypertension: 10-Year mortality in treated elderly hypertensives. J. Hum. Hypertens. 2019, 33, 741-747. [CrossRef]

22. Bobrie, G.; Chatellier, G.; Genes, N.; Clerson, P.; Vaur, L.; Vaisse, B.; Menard, J.; Mallion, J.-M. Cardiovascular prognosis of "masked hypertension" detected by blood pressure self-measurement in elderly treated hypertensive patients. JAMA 2004, 291, 1342-1349. [CrossRef] [PubMed]

23. Franklin, S.S.; Thijs, L.; Hansen, T.W.; Li, Y.; Boggia, J.; Kikuya, M.; Björklund-Bodegård, K.; Ohkubo, T.; Jeppesen, J.; TorpPedersen, C.; et al. Significance of white-coat hypertension in older persons with isolated systolic hypertension: A meta-analysis using the International Database on Ambulatory Blood Pressure Monitoring in Relation to Cardiovascular Outcomes population. Hypertension 2012, 59, 564-571. [CrossRef] [PubMed]

24. Franklin, S.S.; Thijs, L.; Li, Y.; Hansen, T.; Boggia, J.; Liu, Y.; Asayama, K.; Björklund-Bodegård, K.; Ohkubo, T.; Jeppesen, J.; et al. Masked hypertension in diabetes mellitus: Treatment implications for clinical practice. Hypertension 2013, 61, 964-971. [CrossRef] [PubMed]

25. Franklin, S.S.; O’Brien, E.; Thijs, L.; Asayama, K.; Staessen, J.A. Masked hypertension: A phenomenon of measurement. Hypertension 2015, 65, 16-20. [CrossRef] [PubMed]

26. Agarwal, R.; Sinha, A.D.; Light, R.P. Toward a definition of masked hypertension and white-coat hypertension among hemodialysis patients. Clin. J. Am. Soc. Nephrol. 2011, 6, 2003-2008. [CrossRef] [PubMed]

27. Schrader, J.; Lüders, S.; Middeke, M. Antihypertensiva immer abends-Bloß nicht oder sinnvoll? (Antihypertensives always evenings-absolutely not or sensible?). Internist 2020, 61, 980-988. [CrossRef]

28. Parati, G.; Ochoa, J.E.; Bilo, G.; Agarwal, R.; Covic, A.; Dekker, F.; Fliser, D.; Heine, G.H.; Jager, K.J.; Gargani, L.; et al. Hypertension in Chronic Kidney Disease Part 2: Role of Ambulatory and Home Blood Pressure Monitoring for Assessing Alterations in Blood Pressure Variability and Blood Pressure Profiles. Hypertension 2016, 67, 1102-1110. [CrossRef] [PubMed]

29. Yano, Y.; Inokuchi, T.; Hoshide, S.; Kanemaru, Y.; Shimada, K.; Kario, K. Association of poor physical function and cognitive dysfunction with high nocturnal blood pressure level in treated elderly hypertensive patients. Am. J. Hypertens. 2011, 24, $285-291$. [CrossRef]

30. Kario, K.; Schwartz, J.E.; Pickering, T.G. Ambulatory physical activity as a determinant of diurnal blood pressure variation. Hypertension 1999, 34, 685-691. [CrossRef]

31. Guo, H.; Tabara, Y.; Igase, M.; Yamamoto, M.; Ochi, N.; Kido, T.; Uetani, E.; Taguchi, K.; Miki, T.; Kohara, K. Abnormal nocturnal blood pressure profile is associated with mild cognitive impairment in the elderly: The J-SHIPP study. Hypertens. Res. 2010, 33, 32-36. [CrossRef]

32. Goldstein, I.B.; Bartzokis, G.; Guthrie, D.; Shapiro, D. Ambulatory blood pressure and brain atrophy in the healthy elderly. Neurology 2002, 59, 713-719. [CrossRef] [PubMed]

33. Forte, G.; De Pascalis, V.; Favieri, F.; Casagrande, M. Effects of Blood Pressure on Cognitive Performance: A Systematic Review. J. Clin. Med. 2019, 9, 34. [CrossRef] [PubMed]

34. Franklin, S.S.; Jacobs, M.J.; Wong, N.D.; L'Italien, G.J.; Lapuerta, P. Predominance of isolated systolic hypertension among middle-aged and elderly US hypertensives: Analysis based on National Health and Nutrition Examination Survey (NHANES) III. Hypertension 2001, 37, 869-874. [CrossRef] [PubMed]

35. Young, J.H.; Klag, M.J.; Muntner, P.; Whyte, J.L.; Pahor, M.; Coresh, J. Blood pressure and decline in kidney function: Findings from the Systolic Hypertension in the Elderly Program (SHEP). J. Am. Soc. Nephrol. 2002, 13, 2776-2782. [CrossRef] [PubMed]

36. Uallachain, G.N.; Murphy, G.; Avalos, G. The RAMBLER study: The role of ambulatory blood pressure measurement in routine clinical practice: A cross-sectional study. Iran. Med. J. 2006, 99, 276-279. 